This is a post-peer-review, pre-copyedit version of an article published in Subjectivity, 8(2), July 2015. The definitive publisher-authenticated version is

\title{
Subjectivity 2.0: Digital technologies, participatory media and communicative capitalism
}

\begin{abstract}
Drawing on observations and focus group material from pervasive drama project, The Memory Dealer, this article explores both the dynamics and the limitations of existing models of digital subjectivity. It interrogates, in particular, constructions of the digital subject within critical internet studies, focusing on the work of Jodi Dean. This model of subjectivity argues that participatory digital media are a conduit through which the subject is 'captured' and shaped to suit the needs of capital. It is suggested here, however, that framing subjective engagements with technology as inevitably being relations of capture, is dangerous in foreclosing scope for resistance and inter-subjective political action. The article ultimately argues that there is a need to reconceptualise the digital subject away from models of capture and towards a more situated, material analysis of the affordances enabled by subjective entanglements with technology.
\end{abstract}

\section{Keywords}

Digital media; social media; pervasive drama; communicative capitalism; drive; digital subjectivity

\section{Introduction}

Participatory engagements with web 2.0 media have been characterized as 'capturing' subjectivity in ways that inhibit meaningful inter-subjective communication and political agency, whilst giving the illusion of facilitating these processes (Dean, 2009, 2010, 2012). Under the guise of social interaction, the digital subject comments, clicks and 'likes' and - in a context where attention is a source of advertising revenue (Goldhaber, 2006) and personal 
information is a resource to be mined (Andrejevic, 2013) - participation is translated into profit (Lovink, 2011). This characterisation of digital media depicts web 2.0 platforms, particularly social networks, as transforming individual behaviours into a set of resources for consumer capitalism (Berardi, 2009; Fisher, 2009; Grosser, 2014). Digital media are, in other words, framed as the conduit through which subjectivity is shaped to suit the needs of capital, belying narratives that have equated the participatory affordances of digital media with more active audiences (e.g. Jenkins, 2006).

The problem is that this perspective paints a somewhat deterministic picture of digital mediause and depicts, on the one hand, a subject who is passive and politically disengaged and, on the other hand, the technologies of capital as operating to smoothly commodify subjectivity, with no scope for resistance. In response to these problems, this article interrogates the model of subjectivity constructed by critical internet studies, focusing in particular on Jodi Dean (2009, 2010, 2012), due to her work crystallising recent characterisations of this subject. This task is politically pressing, because - if it is possible to contest the depiction of digital media as intrinsically problematic and individualising - this opens space to understand how web 2.0 platforms could form the basis for new modes of intersubjective communication (Terranova, 2012: 12) or be used tactically by activists in ways that resist the commodification of subjectivity (Barassi and Treré, 2012). Departing from the limiting psychoanalytic models of capture that ground Dean's digital subject, ${ }^{1}$ the article thus builds on arguments in this journal that have challenged predetermined models of human-technology relations (Puig de la Bellacasa, 2009; Callus and Herbrechter, 2012; Schraube and Sørensen, 2013). In doing so it offers an alternative model of subjectivity as being constructed through engagements with technological infrastructures, but in ways that do not seamlessly commodify subjectivity and instead create friction and space for resistance. 
To interrogate politically inhibitory framings of the digital subject, and put forward its alternative model of subjectivity, the article initially traces Dean's arguments about the relationship between the captured subject, and the 'communicative capitalist' context in which she situates this subject. As a lens through which to examine this characterisation of subjectivity it then explores how the subject has been constructed in debates surrounding pervasive media, such as internet-enabled mobile devices. To materialize these debates the article draws on focus group findings and observations from pervasive drama project The Memory Dealer (Lander, 2013), as a case-study that is representative of this form of mediause.

\section{Case Study Analysis: The Memory Dealer}

Pervasive, or 'mobile urban', drama are: 'interactive audio plays that let the user be the main character in a drama where the real (possibly responsive) urban environment becomes the scenography' (Hansen, Kortbek and Grønbæk, 2012). These performances use personal digital technologies to transform 'real-life' locations into settings for the drama (Benford and Giannachi, 2011; Evans, 2014a), often combining mediated narrative-content with direct engagements with actors or site-specific set pieces. In the case of The Memory Dealer, smartphones and a dedicated application were used to convey the narrative and lead participants to specific locations at particular times (where they would then engage with 'real' actors), but the predominant setting for the drama was a busy urban area in the U.K. city of Bristol (Evans, 2015). The technologies central to such projects, therefore, are precisely those that have been framed as intensifying engagement with digital media by enabling participation in commercial online activities whilst 'on-the-go' (Manzerolle, 2010; Brophy and de Peuter, 2014). For this reason pervasive drama is a useful focus for exploring constructions of the digitally-mediated subject. 
In addition to the relevance of the technologies used in pervasive drama, the narrative of The Memory Dealer helps to illuminate tensions that are central to constructions of the subject as captured. Set in a near but dystopian future, the plot centres on the commodification of memory. Technologies have been developed that record memories, which can then be downloaded onto smart phones and viscerally re-experienced by others. This process is currently illegal, with a flourishing black market of memory dealing, but is on the verge of legalisation and the U.K. government are brokering a deal with the (somewhat sinister) corporation Mevokia for the rights to all recorded memories. This narrative is spoken from a first person perspective, which encourages participants to embody the role of the nameless protagonist, who becomes embroiled in a plot to prevent the privatization of memory after an estranged friend (Eve) contacts them for help. Eve is currently wanted by the police for her role in activist organisation the XM who are contesting the push to legalise, due to her belief that:

Memories are sacred. They are what make us who we are, they are how we learn, how we relate to other people. The government is selling the right to own all recorded memories to a single corporation. And letting Mevokia control our memories means they will control who we are, how we learn and how we relate to others. I will do anything to prevent this so called legalisation. Anything. (Lander, 2013)

The Memory Dealer, therefore, seems to starkly dramatize the consequences of digital capture and its capacity to transform intimate facets of the self (such as memory) into profitable resources. I suggest, however, that a more complex analysis can be crafted, especially if this plot is contextualised in relation to one of the defining features of pervasive drama: audience participation (Nack and Waern, 2012). ${ }^{2}$ Drawing on focus group findings taken after performances, and observations of audience behaviour in the drama, I suggest that 
by examining tensions in users' engagements with the devices central to the drama, it is possible to highlight the limitations of the model of subjectivity constructed within critical internet studies. In developing these arguments the article facilitates dialogue between the critical-theoretical tradition offered by Dean and research that derives from a media-studies (and specifically audience-studies) perspective.

The iteration of The Memory Dealer discussed here was performed at the Mayfest Arts Festival, Bristol, $24^{\text {th }}-26^{\text {th }}$ May 2013. Groups (ranging from 3-6 participants) began the twohour performance at staggered intervals (with new participants beginning every 30 minutes, between $11 \mathrm{am}-4 \mathrm{pm}$ each day). Our focus groups were formed from these pre-existing participant groups, and were conducted immediately after performances. Over the three days of performances we held over thirty groups, speaking to 124 people in total; all of audience reflections cited here are transcribed from audio-recordings of these discussions.

As Elizabeth Evans and Nanette Nielsen (2015) foreground, despite discussions taking place immediately, participants still had to recall details that - at the time - may have seemed insignificant (such as how they navigated the technologies used). In addition to difficulties in recalling events accurately, other well-established shortcomings of focus groups, such as group dynamics, had potential to discourage particular responses (Morgan, 1996: 140). To counter these issues, we supplemented focus group data with direct observations of participants' engagement in the performance. Members of the research group ${ }^{3}$ were positioned at key 'transition-points' in the drama in order to observe how participants negotiated these transitions (observation-sites included a busy café where participants had to identify a key character; a bridge where people shifted from listening to a monologue to engaging with an actress; and a waiting room scene where the narrative prompted them to perform certain actions). Though focused on a specific performance, and so necessarily limited in scope, these methods nonetheless provide a rich sources of insight about how 
people navigate engagements with participatory digital media platforms in practice that complicate Dean's arguments. The intention, however, is not to use these research materials to crudely substantiate or refute Dean's claims, but to heuristically explore the implications and limitations of communicative capitalism as a framework for understanding contemporary subjectivities.

\section{Communicative Capitalism and Captured Subjects}

Dean's communicative capitalism thesis contends that: 'contemporary communications media capture their users in intensive and extensive networks of enjoyment, production and surveillance' (2010: 3). From this perspective, digitally-enabled participation - on both an individual and collective level - is not only illusory but enriches capitalist networks. ${ }^{4}$

To summarise Dean's arguments, participatory digital media platforms (such as blogs and social networks) trap users in communicative loops, which are driven by unfulfilled desire. These platforms co-opt our desire for collectivity by constantly prompting us to speak and making it seem like these speech acts are a form of interaction. Though we might gain instant gratification this is short lived because the desire to be listened to, and meaningfully engaged with, is unfulfilled in online contexts due to the invariably superficial nature of these interactions. Unfulfilled desire thus solicits a constant stream of activity from users of digital media, to assuage this perpetual sense of dissatisfaction, trapping users in never-ending feedback loops (2010: 31). It is this form of digital 'capture' that Dean frames using her own interpretation of the psychoanalytic concept of drive, which she characterises as the repetitive impulse to act in pursuit of a goal and fail to meet this goal (such finding knowledge, meaning or truth) as these qualities do not really exist in online cultures: :

We enjoy failure. Insofar as the aim of the drive is not to reach its goal but to enjoy, we enjoy our endless circulation, our repetitive loop. We cannot know 
certainly; we cannot know adequately. But we can mobilize this loss, googling, checking Wikipedia, mistrusting it immediately, losing track of what we are doing, going somewhere else. We are captured because we enjoy. (Dean, 2010:

The political significance of drive does not lie on the level of individual subjects, however, but in the relations it forges between subjects and consumer-capitalism (2010: 30). As our communication shifts from 'real-life' to virtual contexts, it becomes data that can be used by marketers, attention that can be sold to advertisers and traffic that boosts share prices (2009: 24). By capturing users, moreover, drive forecloses resistance to capitalism by giving the illusion of collective activity that never truly translates into political action: 'Discussion, far from displaced, has itself become a barrier against action as action is perpetually postponed' (2010: 110). These claims will be interrogated further, in relation to The Memory Dealer, but before doing this it is necessary to flesh out precisely how these arguments challenge existing research that has stressed the political potential of digital media for activists or explored its potential to foster more active audiences.

Digital Media, Inter-subjective Action and Political Activism:

Communicative capitalism challenges work that has argued, although digital media act as a conduit for capital, they simultaneously create the material tools, socio-economic forces and symbolic frameworks with which to articulate alternatives to neoliberalism (Castells, 1996, 1997; Hardt and Negri, 2001, 2005, 2009). Whilst acknowledging that digital media can be used for purposes of surveillance and control (Pickerill, 2003; Hands, 2013), thinkers from a range of disciplines, including cultural geography, communications studies, anthropology and critical theory, have argued that these media have nonetheless been pivotal to the work of the new social movements who have articulated alternatives to neoliberalism during the past two decades (Pickerill, 2003; Downing, 2008; Escobar, 2008; Hands, 2010). 
Dean has always expressed cynicism about the truly radical potential of these technologies (Passavant and Dean, 2004), but her analysis of web 2.0 platforms exacts her most totalizing critique, in asserting that these media displace political activism with 'clicktivism' and concrete action with online speech acts, which fail to cohere as critical discussion (2009: 32). Dean suggests, furthermore, that even uses of digital media to mobilise individuals is counter-productive, as online dissent feeds back into the commercial networks through which it is disseminated: 'perpetually expanding the topography of struggle even as it constantly signals the locations, intentions and networks of those who are fighting' (2010: 125).

Dean's arguments thus contribute to recent work that has tempered the cautiously optimistic accounts of early internet activism and undertaken a more critical assessment of digital media (for an overview see Barassi, 2013), by suggesting that social networks support a mode of protest based on aggregation rather than networking, with individuals brought together (as the 99\%, for instance) due to the aggregation of individual interests without always being meaningfully or sustainably connected (Juris, 2012: 267). These arguments seem to be substantiated by research focusing on specific protest movements, where both theoretical and more empirically-focused work shares Dean’s concerns about valorising social media’s role in protest. This is crystallised by the profound difficulties that have faced some of the most well-known early participatory engagements with technology, such as the Indymedia alternative news network, which was pioneered by activists in the early '00s in order to give ordinary people a platform to speak (Allan, 2005; Gilmor, 2006). In his auto-ethnographic analysis of the network's decline, for instance, Scott Uzelman claims that the participatory features of the network have been co-opted and used as a selling point by commercial web 2.0 media platforms such as blogs and social networks (Uzelman, 2011: 283), an argument borne out by my own research that has traced the migration of activists to web 2.0 platforms and mapped a steep decline in the network between 2010-2014 (Giraud, 2014: 425-6). 
More recent activist engagements with social media have also been problematized in ways that resonate with Dean's arguments; discourses of 'Twitter revolutions' in relation to the ‘Arab Spring', for instance, have been criticized extensively. Criticisms levelled at the network are numerous, but include it gaining publicity from dissent (Morozov, 2009a); leading to the surveillance and repression of protestors (Ems, 2014); being used as a tool of 'soft power' in political struggles between the U.S. and regions it has a vested interest in (Burns and Eltham, 2009); ‘skewing’ participation towards ‘educated elites’ (Etling et al, 2010: 1240) and failing to translate fully into offline action (Lim, 2012).

What these analyses, both of Indymedia and of 'Twitter Revolutions' emphasise, however, is that - whilst techno-utopianism should be avoided - digital media can still aid social movements with pre-existing political grievances and aims, by acting as: 'both as [the] technology and space for expanding and sustaining the networks upon which social movements depend' (Lim, 2012: 234). Though some aspects of recent research into activist engagements with digital media seems to support Dean's claims, therefore, ethnographic studies of activist praxis suggest that movements still exert agency in navigating the vertical power relations of these media and turning them towards more egalitarian ends (Kavada, 2013), by developing tactics to circumvent these technologies' commercial agenda and undermine their capacity to be used for surveillance (Barassi and Treré, 2012). Echoing Dean, the limitations of digital media (limitations that were, it is important to note, even acknowledged in early accounts of the political potential of digital media, e.g. Pickerill, 2003) seem to have become more pronounced with the rise in web 2.0 platforms. Research focused how these media are used in practice, however, paints a much messier picture of digital media use than the communicative capitalism thesis suggests, by emphasising the ongoing promise of these media as well as the new problems that they pose.

Digital Media and the Commodification of Subjectivity: 
Theoretical work on individual identity follows a similar trajectory to discussions of intersubjective action, with thinkers who were broadly positive about the participatory potential of digital technologies (Turkle, 1995; Morozov, 2009b) displaying increased cynicism (Turkle, 2011; Morozov, 2011, 2013). Even early champions of digital media’s political potential have, more recently, acknowledged that: “"participatory culture” has become an empty signifier often used in very superficial ways by all kinds of groups that want to entice our participation but do not want to give up any real control' (Jenkins, in Jenkins and Carpentier, 2013: 2). These arguments lend weight to Dean's claim that communication: 'reformats ever more domains of life in terms of the market: What can be bought and sold? How can a practice, experience, or feeling be monetized?' (2009: 24). Digital media - especially social networks - are seen as connecting individual subjects with consumer capitalism, making public our private selves, in order to transform the self into a set of resources rather than a stable framework for identification (boyd, 2008; Hancock and Garner, 2014).

This is an intensification of the 'networked individualism' (Castells, 2005) or 'network sociality' (Wittel, 2001) discussed in the early 00s, where individuals' communal bonds developed through experience are displaced by repetitious and trivial interactions: a prescient argument in light of Facebook's 'like' button. Such forms of sociality are opposed to notions of ‘community' as ‘social relations are not “narrational” but informational; they are not based on mutual experience or common history but primarily on an exchange of data and "catching up”' (Wittel, 2001: 51). For Dean this reflects the way that: 'communicative capitalism fragments thought into ever smaller bits, bits that can be distributed and sampled, even ingested and enjoyed, but that in the glut of multiple, circulating contributions tend to resist recombination into longer, more demanding theories’ (Dean, 2010: 2). Not only, therefore, does this pose a threat to the more participatory audiences that certain commentators argue 
can rejuvenate more critical perspectives towards the mass media (Meikle, 2008), but also to the potential for inter-subjective political action based on mutual understanding (Hands, 2010).

Yet, just as there is a growing body of work that acknowledges the problems that social media pose for politics, whilst still stressing their value for activists, a number of theorists have balanced a critical appraisal of social media with a non-deterministic understanding of these technologies. Though sharing Dean's concerns about the commodification of attention, for instance, Tiziana Terranova argues that - by depicting attention as a scarce resource discourses of the attention economy not only construct an 'impoverished subject' (2012: 7) but one whose cognitive capacities are technologically determined. For Terranova, therefore, this results in a reductive account of subjective engagements with digital media, which cannot 'account for the powers of invention of networked subjectivities' or the potential for the 'new forms of social relations grammatised by social networks [to] produce new conditions of transindividuation (2012: 12-13). A burgeoning body of ethnographic work, moreover, has suggested that the affordances of communications media are established through intersubjective practice (Madianou and Miller, 2013; Cammaerts, 2014) and emerge through their broader socio-technical milieu, rather than being intrinsic to the technologies themselves (Ash, 2014). In offering a model that is simultaneously critical of digital media, yet refuses to prescribe rigid models of subjective engagements with these technologies, conceptions of technological affordances offer valuable tools for reconceptualising the digital subject. Before exploring the potentials of this body of work in more depth, however, it is necessary to develop a sympathetic critique of Dean's concept of drive, and elucidate the limits of 'capture' as a means of understanding digital subjectivities by turning to The Memory Dealer.

\section{Exploring the Limits of Drive}


The Memory Dealer is drawn on to illuminates the dynamics and limitations of drive in three key ways: Firstly, it is used to elucidate the mechanisms of drive; the drama's plot, for instance, focuses on the commodification of memory, with smartphones acting as the device through which this commodification occurs, as people become addicted to viscerally experiencing others' memories whilst voluntarily uploading and sharing their own intimate experiences.

The performance is, secondly, used to elaborate on Dean's account of the relationship between digital subjects and communicative capitalism, illustrating how even projects which critique individuals' engagement with digital media (such as The Memory Dealer itself) can become recuperated by commercial logic (Tuters, 2012). This is because, while the plot of The Memory Dealer parodies digital culture, its own use of smartphones to make public space 'playable' could be seen as perpetuating the commercial logic of 'gamification'. 5

However, while The Memory Dealer initially seems to bear out Dean's arguments it ultimately problematizes conceptualisations of the captured subject. The final section of the article thus interrogates the limits of this construction of subjectivity, using The Memory Dealer to - thirdly - illustrate how instrumental uses of technology can be thwarted by friction generated when these technologies break-down, defy expectations or do not seamlessly integrate into existing socio-technical infrastructures. For Dean, resistance can only emerge from breaking the circuits of drive, at the end of Blog Theory (2010) we are left with the bleak conclusion that the only way of breaking these cycles is through hacktivism and directly disrupting technological infrastructures. Through reflecting on focus group findings and observations of The Memory Dealer, and drawing on theoretical debates about infrastructure, I argue instead that resistance can emerge immanently through everyday engagements with technology. 


\section{Dramatizing Drive}

The Memory Dealer's dramatization of the commodification of memory is useful in interrogating characterizations of the 'captured' digital subject. On a very straight-forward level, people become captured through their consumption of others’ memories: ‘...stumbling around plugged into their headphones memmed out of their heads. That vacant look, bodies here, but their minds somewhere, or someone else' (Lander, 2013). 'Memming' thus epitomises Dean's characterisation of the subject captured by participatory online culture, due to entirely destabilising coordinates that could anchor individuals' symbolic sense of self: 'Without stable points of symbolic identification, whatever beings oscillate between the imaginary and the Real, crafting their ever adaptable, morphing, identities even as they remain threatened and vulnerable to the success, presence, and enjoyment of others' (Dean, 2010: 92).

While memories can be experienced and give instant pleasure, they simultaneously engender dissatisfaction in being other people's memories, dissatisfaction that is compounded because this cycle of consumption acts as a barrier against crafting meaningful memories of their own. This parallels Dean's argument that there are no longer any gaps between the imaginary and Real that allow genuine access to it: 'Insofar as digital environments enable the realization of fantasies on the textual screen, they close the gaps between the subject's symbolic identity and its phantasmic background. Instant gratification fills the lack constitutive of desire' and 'fantasies that are realized cease to be fantasies'. This ultimately means that the digital subject loses 'the sense of an underlying Real' (2010: 8). 'Memming', therefore, helpfully elucidates the dynamics of drive, in portraying the cycles of gratification and failure, which Dean sees as capturing the subject and prohibiting political action. Eve, the protagonist, moreover, epitomizes the captured subject who can only gain agency through 
rejecting memory consumption altogether and intervening in the further commodification of ‘memming'.

\section{Audience Responses to Digital Addiction}

Whilst the plot of the drama helps to illuminate the dynamics of drive, and the way it depicts a subject entirely captured by the mechanisms of capitalism (via their engagement with digital media), audience responses to the drama complicate this construction of subjectivity. The drama's critique of self-commodification was acknowledged by audiences, who interpreted it as having an explicitly anti-capitalist message:

Capitalization, Capitalism, et cetera, yes ... that subtext was there for me throughout

(Friday 12.30, participant 1)

And discussed how it reflected their own anxieties over the relationship between technology and the self:

Something I have considered in my life as well that they might want our store of memories, even if it is just like the physical memories we have created on tapes and stuff, if feels like they could just kills us off and watch us forever now. (Friday, 16.00, participant 2)

The narrative also engendered explicit resistance to memory-commodification, with participants - almost unanimously - declaring their sympathy to the illegal activities of the $\mathrm{XM}$ activists in the focus groups.

Sympathy to the activist cause was illustrated in particular by responses to the final scene of the drama, in which participants risked arrest due to an apparent double-crossing by their 'friend' and had to make a collective decision about whether to leave (to avoid the police) or 
remain as Eve has asked them to do (which - she contended - would facilitate her escape and be good for the 'cause'). This scene, therefore, prompted dialogue between participants, who not only engaged in discussion about the ethics of 'memory dealing' but had to make a collective decision about whether to stay or go. In the focus groups we found that the majority of participants chose to remain in order to combat memory privatisation:

...we kept on talking about it and decided we didn't want the corporation to take over all the memories and that was the really reason for staying...

(Friday, 16.00, participant 2)

This sympathy to the cause occurred despite participants' suspicion of Eve herself:

I would potentially sacrifice my well-being for the cause but I wouldn't have sacrificed my well-being for her because I haven’t seen her for years and she is just not trustworthy anyway

(Friday, 15.30, participant 2)

I don't think it was about trusting Eve, I think it was about the bigger picture. (Saturday, 11.00, participant 3).

By encouraging the dialogical formulation of decisions, and eliciting discussion about the commodification of identity, The Memory Dealer demonstrates the capacity of digital media to generate critical reflection and encourage participatory audience cultures. These reflections, moreover, were not simply the audience passively accepting the ideological trajectory of the narrative, as their observations extended beyond the plot with several participants commenting critically on everyday uses of the mobile technologies that were highlighted through uses of these technologies to disseminate the narrative:

'You notice how many people who do have headphones in...' 
'It's amazing, the number of people who walk around the streets, headphones

in...’

'And you think, are you involved in this or are you just on your phone?'

' But why do they all look at their phone when they’re walking?'

(Sunday, 12.00, dialogue between participants 1 and 2)

On the one hand, therefore, The Memory Dealer portrays the captivating dynamics of drive (resonating with Dean), but on the other hand it uses digital media to encourage audiences to critique the commodifying potentials of these technologies. This is explicit not only on a narrative level, where participants empathised with the XM, but also in its use of technology, which fostered broader reflection about participants' everyday uses of technology that went beyond the questions facilitated by the narrative itself. Whilst playing on fears about the potential of digital media to 'capture' subjects in some way, therefore, the drama also deconstructs notions of 'capture' by insisting on more active forms of media-engagement.

\section{Pervasive Drama and Participatory Subjects}

In order to avoid simplistic uses of audience responses as revealing an underlying 'truth' about subjective relations with technology, however, the above issues need to be contextualised in relation to debates about whether pervasive drama is genuinely participatory or simply uses 'participation' as a selling point. Pervasive drama has been framed as a media art-form that crystallises the shift from 'passive' audiences to active 'prosumers' of content (Evans, Flintham and Martindale, 2014), which has often been used to characterise digital cultures more broadly (Jenkins, 2006). As such, it is a useful lens through which to explore debates about whether this participation is politically significant, or has been co-opted for commercial ends and instead contributes to the forms of capture characterised by Dean. 
Pervasive drama builds on a lineage of sound and performance art, from simple uses of Walkmen or iPods to disseminate narrative about sites within sound art projects (Butler, 2006; Barnes, 2013), to the use of GPS-enabled smartphones and geo-tagging to engender engagement with specific locations (Active Ingredient, 2009). Such projects have been positioned as part of a longer Situationist lineage, due to their capacity to facilitate 'semidérives’ (Butler, 2006), enable engagement with urban psychogeography (Barnes, 2013), and defamiliarize everyday commercial spaces (Bull, 2007). These narratives, for instance, often encourage players to wander around their environs and pay closer attention to their apparently mundane surroundings. This is illustrated by the opening of The Memory Dealer:

You're going to meander, soak up the city. Where ever your feet take you. How many times have you walked here? Now you find yourself really starting to notice things around you. Familiar things. Things you never noticed before. And now that you think about it you realise you often walk around without even seeing where you are. Rushing on with your life, the fabric of the world all but invisible. (Lander, 2013)

While participants ultimately have a narrative to follow (hence the addition of 'semi' to the concept of the dérive, when it is applied to such projects; Butler, 2006), they are still encouraged to attune themselves to their surroundings, with players asked to walk slowly, out of step with the rhythms of their busy commercial locale. The drama, therefore, fosters behaviour that runs contrary to instrumental commercial logic that ordinarily regulates movement in urban locations (Merrifield, 1993).

Marc Tuters points out, however, that these participatory values have gradually been recuperated, as locative-media have been used by commercial entities to exert fine-tuned control over individual actions. This is epitomised by games such as Foursquare or 
Facebook’s 'check-in' option (de Souza e Silva and Frith, 2010), which map people’s leisure activities in real-time and display them on social networks (illustrating the prescience of Howard Rheingold's description of mobile phones as an 'always on panopticon'; 2002: 183). Foursquare even transforms these actions into a competition (if you frequent a location more than anyone else you are made its virtual 'mayor'!). Tuters argues, therefore, that play itself has become commodified as games gather our personal data (under the guise of turning empty time into more entertaining experiences), and rationalize our actions in line with commercial logic (2012: 269-270).

\section{Participation as 'Bottom-Up' Control?}

Whilst the narrative of The Memory Dealer is explicitly critical, its use of smart phones could be seen as perpetuating the commercial logic that it is attempting to critique, in line with Tuters's argument that: 'in today's new media landscape the idea of play as a mode of oppositional politics seems somewhat nostalgic' (Tuters, 2012: 269). Though computer games themselves have already been argued to naturalise capitalist values (Dyer-Witheford and de Peuter, 2007), the extension of gaming logic to everyday life was originally seen as creative and oppositional due to its association with the Situationist-inspired artistic projects outlined previously (Butler, 2006). As touched on above, these projects were seen as having the capacity to defamiliarise the everyday, but can now been seen as recuperating subjective creativity for commercial ends. Tuters suggests: 'such projects seemed, metaphorically at least, to inscribe the emancipatory project of said theory within a calculative logic largely determined by this formerly military technology (2012: 269-70).

The recuperation of 'play', however, is not solely due to locative technologies embodying the logic of top-down control, but people voluntarily subjecting themselves to 'a bottom-up mode of control' (Tuters, 2012: 270). Facebook and locative games epitomize this process due to relying on competition between friends that necessitates constant peer-surveillance (Jacobs, 
2012). These games, again, transform everyday activities into data for comparison with others (reinforcing the trends identified by Dean), then enable this data to become marketing information that enriches the social networks through which it is circulated. This intersects with Dean's own arguments about Situationism, where she suggests that Debord's analysis fails to consider that control does not have to be 'top-down' but can be self-imposed. This critique of Debord feeds into Dean's wider criticism of digital 'cheerleaders', as she contends that praise of digital media's participatory value is grounded in the assumption that control is always 'top-down': 'If the problem of the image is that it comes from "someone else" then participatory technology is the solution' (2010: 109). She argues that this analysis neglects to consider that today's participatory culture can itself contribute to the spectacle (109). For Dean the subject's constant interaction, constant comparison with others, is what entraps them, rather than their inability to have a platform for speech.

Though pervasive drama does not necessarily commodify in itself, its manipulation of subjective experiences could be seen as integral to it as a media-form and illustrate how participatory media projects can contribute, rather than contest, spectacular culture. Indeed, participants of The Memory Dealer directly referred to feelings of 'manipulation' (Sunday, 11.00, participant 3) and unease at the limited nature of the participation offered:

I'd have liked generally to be given completely free reign to go and explore stuff, or constrained and it's quite obvious what to do next, and they seemed to be a kind of, we want you to explore but in this very specific way that we're not quite going to tell, and that just left me slightly tense going through it

(Friday, 11.00, participant 4)

This account of pervasive drama, however, neglects the more complex dynamic not only of creative projects such as The Memory Dealer, but of subjective engagements with technology 
more broadly. Indeed I suggest that the very fact that people reflected unease at manipulation is indicative of something more complex occurring, not only at the level of narrative, but in relation to the technologies used to disseminate it.

\section{Technological Friction}

Communicative capitalism assumes a straight-forwardly instrumental relationship between technology and capitalism, and it is here that the construct of the captured subject really reveals its limitations. Accounts of technological affordances, for instance, as discussed earlier, paint a more complex picture, in suggesting that digital media have their attributes defined relationally through the milieu in which they are used (Ash, 2014). These attributes emerge via processes that range from remediation (the social uses of older technologies influencing people's engagements with new ones) to novel cultural norms becoming attached to specific media within a community due to the specific needs and values of that community (Madianou and Miller, 2013). Mirca Madianou (2014), for instance, illustrates how different applications can have different affordances, which have emerged through being used for different purposes even though they have the technological capacity to perform similar functions. She outlines how shifting between different smartphone applications enables Filipino teenagers to manage their social relationships, due to the varied affordances associated with different apps; for example, teenagers often switched from instant messaging to email in order to gain autonomy from their parents (due to IM being perceived as demanding an instant response, whilst it is socially acceptable to have a time lag between emails). These arguments parallel analyses of activist uses of social media, which have emphasised how platforms can develop new norms (and challenge the commercial imperatives built into them) through being used tactically by activists (Barassi and Treré, 2012). Such understandings of affordances do not frame technological attributes as entirely 
socially constructed, therefore, but foreground that attention needs to be paid to ways that digital media are used in practice.

As Andrew Goffey suggests (2013), moreover, if technology is constructed as a conduit for the mechanisations of capital then this ignores the problem of translation between instrumental ideals and their realisation through technological design. Translation, in this sense, is a term derived from actor-network theory that stresses how technologies are 'endowed with the capacity to translate what they transport, to redefine it, redeploy it, and also to betray it' (Latour, 1993: 81). Goffey argues (with Matthew Fuller) that further attention needs to be paid to the technicalities of how management ideals are realised, as messy realities often intervene in abstract ideals about how technologies 'should' function (Fuller and Goffey, 2013).

A focus on technicalities has profound political significance because it reveals associated ‘cultural techniques’ (Macho, 2013; Winthrop-Young, 2013) - practices related to specific technologies ${ }^{6}$ - that 'participate in the formation of subjects, as well as constitute ways of knowing and organising social reality' (Parikka, 2014: 30). The reality that these techniques attempt to construct, however, is not always borne out in practice. Jussi Parikka (along with Fuller and Goffey) uses call centres to illustrate this process as they are composed of subjects and technologies that are linked together by associated 'techniques', which fragment and regulate behaviour "in ways that produce "the cognitive" as a matter of regularisation and disciplinary formation'. The 'idealisations found in organisational charts', however, do not necessarily map onto social reality 'if one understands by that the number of exceptions, bugs, errors, glitches, mishearings and other events that occur amid actions and expressions' (Parikka, 2014: 41). It is important, therefore, not to generalize about the subject-technology relation, and to develop a closer understanding of these technicalities and their weaknesses. 
Discussions of cultural techniques and the relational affordances of digital media contrast with Dean's framing of technologies as being instilled with ideological imperatives, which are straight-forwardly realised through their shaping of subjectivity. Whilst acknowledging the capitalist context of digital media, for instance, Fuller and Goffey argue that technologies cannot unproblematically serve neoliberal ends. As an intermediary that takes an active role in translating these imperatives, digital media could instead 'betray' any instrumental intentions. Though ANT itself has been criticised for its apolitical tendencies (for a sympathetic critique see Puig de la Bellacasa, 2013), Fuller and Goffey indicate how a focus on the technicalities of specific technologies does not have to reduce debate to a set of dry technological concerns and is politically important in revealing scope for subjective agency.

\section{Sites for Subjective Resistance}

In line with these arguments, both the power and the weakness of technological infrastructures lies in their construction of 'ideal' types (of subjects, objects and practices). Although 'procedural chains and connecting techniques give rise to notions and objects that are then endowed with essentialized identities’ (Winthrop-Young, 2013: 11), the coherence of these structures hinges on everything then conforming to these idealisations. Things rarely, however, function as 'ideal types', which means that technologies cannot easily 'domesticate' subjects (Prasad, 2005). As highlighted by the 'glitches' evoked by Goffey and Fuller, friction between the 'ideal' and cultural reality occurs on an everyday basis through our relations with digital media.

A route into politicizing this friction is offered by Susan Leigh Star (1991), who argues that standardization inevitably leads to exclusions of individuals who do not 'fit' with or resist these standards (using her own allergy to onions to illustrate her failure to 'fit' with McDonald's systems). Failure to 'fit' requires 'invisible work' in order to construct an identity that can live safely within these standards (29). One way of contesting these 
structures is thus through 'refusing those images of the executive in the network that screen out the work that is delegated'. Star argues that: 'when this invisible work is recovered [...] a very different network is discovered as well' (29). If practices associated with a technology are seen as seamlessly shaping subjectivity then they are impossible to challenge. In accordance with arguments about subjectivity and materiality (Puig de la Bellacasa, 2009; Schraube and Sørensen, 2013), however, if the focus is on the invisible work needed to realise a subject-position that 'fits', then attention can be turned to this 'invisible network' to ask questions about whether things could be 'otherwise' (Star, 1991: 29). For Star, the diverse practices associated with technological infrastructures do not construct a consumeridentity (as with the model of captured subject), but multiple realisations of subjectivity (see also Mol, 2002). As Star argues: 'McDonald's appears to be an ordinary, universal, ubiquitous restaurant chain. Unless you are: vegetarian, on a salt-free diet, keep kosher, eat organic foods, have diverticulosis [...], housebound, too poor to eat out at all - or allergic to onions' (37). While some subject-positions can be easily 'captured' or 'targeted' by the mechanisms of capital (Star-as-McDonald's consumer, for instance), some cannot (Star-asallergic-to-onions) and it is the friction between resistant selves and standardizing structures, which generate space for asking whether social reality could be configured differently.

Even in Dean's own terms, this analysis tests the limits of her account of drive. Technological frictions can create the gaps between fantasy and reality that, Dean argues, are needed to orient political subjects. This is reflected in The Memory Dealer on a simple level, when technological problems meant participants could not be 'controlled' by the technologies used in the drama. This was illustrated in particular by the second scene, when players were supposed to encounter an actress, after spending the first fifteen minutes on a semi-dérive (wandering where they chose around Bristol harbourside, whilst listening to a short monologue). Difficulties in understanding the application, or in some instances technical 
problems with it, however, meant that the actress eventually had to bring a bicycle to traverse the area quickly and orient participants!

Cultural tensions thus arose due to the drama intentionally playing with the conventions of existing listening cultures. As Evans argues (2015) pervasive drama requires participants to shift between different reading strategies, with the multiple media platforms used in such projects requiring knowledge of different media literacies. This shifting between literacies, or the novelty of certain platforms, led to some players facing anxiety over whether they had 'got it right' (indeed, this was a recurring concern within focus groups). The affordances of the technologies used in this context, in other words, had not yet congealed so confusion could not be resolved solely through technical know-how. Instead we observed players taking constant cues from their peers about how to engage 'properly', often choosing to stay in groups - even when the application or the narrative instructed them to do things alone - to gain reassurance they were doing the 'right' thing. Resonating with Star, participants also assumed multiple identities in the drama: as the audience, as part of the plot, as people who had (or lacked) technical knowledge, as psycho-geographers, and - in the context of the focus groups - as critics. The infrastructure supporting the drama did encourage the enaction of specific forms of subjectivity (predominantly 'engaged-participant'), but the complexity of forging this subject-position through its practices, meant that there was never a neat mapping between audience and the subject position(s) constructed for them. While this analysis cannot ground grand claims about participatory audiences, therefore, it does illustrate problems with assuming a straight-forward translation between ideals (even creative ones), technologies and subjects.

\section{Conclusion}

Dean's account of communicative capitalism is important in politicizing everyday engagements with digital media, but there are limitations to the construction of digital 
subjectivity that it engenders. The reliance on 'drive' forecloses space for resistance and simplifies the relationships between technological 'users' and the technologies they use, whilst also over-stating the instrumental nature of technology. Framing the digital subject in this way makes it impossible to use technology for the purposes of resistance or to conceptualise a digital subject who is not already 'captured'.

Pervasive drama has been used here to both illustrate and sympathetically critique Dean's arguments. The Memory Dealer crystallises Dean's account of drive in its narrative content, with themes such as the commodification of memory, the danger of technological dependency and the reflexive nature of this capture (which destabilises any chance of symbolic identification). 'Mem-heads' are trapped in the cycles of instant gratification, selfaware failure, and repetitive consumption despite this failure, which characterise communicative capitalism. On a technical level the drama also illustrates the displacement of playful forms of resistance with bottom-up modes of control, as 'play' becomes technologically mediated. In a sense, therefore, The Memory Dealer enacts exactly what it is critiquing, albeit for dramatic effect.

Participants' engagements with the drama, however, can helpfully complicate these totalising accounts of digital subjectivity, by indicating how friction generated by the technologies themselves can (in Dean's terms) create the gaps necessary to separate fantasy from reality and provoke critical reflection. These material engagements foreground how this model of subjectivity might not be helpful, by suggesting that drive can never circulate as freely as is suggested in accounts of communicative capitalism. Instead, subjects' failure to 'fit' with the standards prescribed by these technologies can facilitate forms of productive friction and create scope for these technologies to be used tactically for forms of resistance rather than neatly commodifying dissent. Taking technology seriously, therefore, can illustrate the 
dangerous limits of communicative capitalism's model of subjectivity, whilst offering an alternative model of distributed subjectivity that offers space for political resistance.

\footnotetext{
${ }^{1}$ This is not to label all forms of psychoanalysis as 'narrow' (as several articles indicate here, psychoanalytic approaches can productively unsettle cultural discourses of addiction), but is meant in specific reference to the trope of addiction within critical internet studies.

${ }^{2}$ The actual agency given to audiences is a source of debate, with authors highlighting tensions between artists' desire for narrative control versus the push to give audiences genuine agency. This varies between dramas that conform to more conventional narrative structures with a pre-defined end-point (such as The Memory Dealer itself), versus more 'game-like' projects where users actively influence the plot-development (see Evans, Flintham and Martindale 2014).

${ }^{3}$ The 'Moving Experience' research group consists of researchers, from media studies, music, computer science and practice-based backgrounds, who are interested in a range of aesthetic, aural, technological and political questions in relation to the production and consumption of pervasive drama (Moving Experience, N.D.).

4 Dean's arguments have evolved, with earlier work suggesting that digital media still has potential for collective action (Dean 2006), in contrast with a more pessimistic outlook in the wake of Occupy and the global social justice movement before it (Dean, 2012, 2013).

${ }^{5}$ Everyday experiences being transformed into games (Detarding et al, 2011).

${ }^{6}$ It is important to stress that cultural techniques do not solely refer to 'skills, aptitudes and abilities' associated with different technologies (Winthrop-Young, 2013: 6), though this is one of their historical meanings. Instead subjects and technologies are argued to emerge processually, through the techniques that constitute these relations, which themselves evolve-through-relation (Winthrop-Young, 2013: 11).
}

\section{References}

Active Ingredient (2009) I Am AI. [Online] available from: http://www.i-am-ai.net/ [Accessed 23/2/13]

Allan, S. (2005). Online News. Maidenhead: Open University Press.

Andrejevic, M. (2013) 'Estranged Free Labour'. In: T. Scholz (ed.) The Internet as Playground and Factory. London and New York: Routledge. 149-164.

Ash, J. (2014) 'Technology and Affect: Towards a Theory of Inorganically Organised Objects'. Emotion, Space and Society. 14(1): 84-90.

Barassi, V. (2013) 'Review - Networks of Outrage and Hope’. E-International Relations.

[Online] available from: http://www.e-ir.info/2013/02/27/review-networks-of-outrageand-hope/ [Accessed 23/2/13]

Barassi, V. and E. Treré (2012) 'Does Web 3.0 Come After Web 2.0? Deconstructing Theoretical Assumptions Through Practice'. New Media \& Society. 14(8): 1269-1285.

Barnes, S. (2013) 'Sounds Different: Listening to the proliferating sounds of technological modernity in the city'. Space and Culture. 17(1): 4-15.

Benford, S. and G. Giannachi (2011). Performing Mixed Reality. Cambridge, Mass: MIT Press.

Berardi, F. (2009) The Soul at Work. Cambridge, Mass: MIT Press.

boyd, d. (2008) 'Facebook’s Privacy Trainwreck : exposure, invasion, and social convergence’. Convergence. 14(1): 13-20.

Brophy, E. and de Peuter, G. (2014) 'Labours of Mobility: Communicative Capitalism and the Smartphone Cybertariat'. In T. Swiss et al (eds) Materialities and Imaginaries of the Mobile Internet. New York, NY: Routledge. 60-84.

Bull, M. (2004) 'No Dead Air! The iPod and the culture of mobile listening'. Leisure Studies. 24(4): 343-355.

Bull, M. (2007) Sound Moves: iPod culture and urban experience. London and New York: Routledge. 
Burns, A. and B. Eltham (2009) 'Twitter Free Iran'. Communications Policy and Research Forum. [Online] available from: http://vuir.vu.edu.au/15230/1/CPRF09BurnsEltham.pdf [Accessed 20/2/2015.]

Butler, T. (2006) 'A Walk of Art: the potential of the sound walk as practice in cultural geography’. Social and Cultural Geography. 7(6): 889-908.

Callus, I. and S. Herbrechter (2012) 'Posthumanist Subjectivities, or, Coming After the Subject'. Subjectivity. 5(3): 241-264.

Cammaerts, Bart (2014) Movement Media as Technologies of Self-mediation In: Atton, Chris, (ed.) The Routledge Companion to Alternative and community media. Routledge, London, UK.

Castells, M. (1996) The Rise of the Network Society. Oxford: Blackwell.

Castells, M. (1997) The Power of Identity. Bodmin, Cornwall: Blackwell.

Castells, M. and G. Cardoso (2005) The Network Society From Knowledge to Policy. Washington, Mass: Center for Transatlantic Relations. [Online] available from: http://www.umass.edu/digitalcenter/research/pdfs/JF_NetworkSociety.pdf\#page=28 [Accessed 29/4/14.]

De Souza e Silva, A. and J. Frith (2010) 'Locative Mobile Social Networks: Mapping Communication and Location in Urban Spaces’. Mobilities. 5(4): 485-506.

Dean, J. (2009) Democracy and Other Neoliberal Fantasies: Communicative Capitalism and Left Politics. Durham \& London: Duke University Press.

Dean, J. (2010) Blog Theory. Bodmin: Polity.

Dean, J. (2012) The Communist Horizon. London and New York: Verso.

Dean, J. (2013) 'Society Doesn't Exist'. First Monday. 18(3-4). [Online] available from: http://firstmonday.org/ojs/index.php/fm/article/view/4616/3419 [accessed 12th July 2014]

Deterding, S. et al (2011) 'From Game Design Elements to Gamefulness’. Mindtrek, Tampere. [PDF] available from: http://85.214.46.140/niklas/bach/MindTrek_Gamification_PrinterReady_110806_SDE_ accepted_LEN_changes_1.pdf [Accessed 1/12/13]

Dyer-Witheford, N. and G. de Peuter (2007) Games of Empire. Minneapolis: University of Minnesota Press.

Downing, J. (2008) 'Social Movement Theories and Alternative Media: an evaluation and a critique’. Communication, Culture and Critique 1: 40-50.

Ems, L. (2014) 'Twitter's Place in the Tussle: How Old Power Struggles Play Out on a New Stage'. Media, Culture \& Society. 36(5): 720-731.

Escobar, A. (2008) Territories of Difference. Durham and London: Duke University Press.

Etling, B. et al (2010) 'Mapping the Arabic Blogosphere: Politics and Dissent Online'. New Media \& Society. 12(8): 1225-1243.

Evans, E. (2014) “"It’s Probably Just Me”: The literacies of pervasive sound narratives'. Journal for Sonic Studies. 9(1).

Evans, E. and N. Nielsen (2015) 'Editorial of special edition of the Journal of Sonic Studies, on The Memory Dealer’. Journal of Sonic Studies. 9(1).Evans, E., M. Flintham and S. Martindale (2014) 'The Malthusian Paradox: performance in an alternate reality game'. Personal and Ubiquitous Computing.

Fisher, M. (2009) Capitalist Realism. Ropley, Hants: Zero Books.

Fuller, M. and A. Goffey (2012) Evil Media. Cambridge, Mass: MIT Press.

Gilmor, D. (2006). We Are Media. Sebastopol: O'Reilly.

Giraud, E. (2014) Has radical participatory online media really 'failed'? Indymedia and its legacies. Convergence: The international journal of research into new media technologies. 20(4): 419-437. 
Goffey, A. (2013) 'Position Paper in Response to Jodi Dean's Blog Theory'. Jodi Dean Study Day. Unpublished conference paper at: Centre for Critical Theory, University of Nottingham, 21/3/13.

Goldhaber, M. (2006) ‘The Value of Openness in an Attention Economy’. First Monday. 11(6). [Online] available from: http://pear.accc.uic.edu/ojs/index.php/fm/article/view/1334/1254 [Accessed 24/2/15]

Grosser, B. (2014) 'What Do Metrics Want?'. Computational Culture. 4. [Online] available from: http://computationalculture.net/article/what-do-metrics-want [Accessed 19/2/15]

Hancock, B.H. and R. Garner (2014) 'Erving Goffman: Theorizing the self in an age of advanced consumer capitalism'. Journal for the Theory of Social Behaviour. [Online] available from: http://onlinelibrary.wiley.com/doi/10.1111/jtsb.12062/pdf [Accessed 29/4/14]

Hands, J. (2010) @ Is For Activism. London: Pluto Press.

Hands, J. (2013) 'Introduction: Politics, Platforms and Performativity’. Culture Machine. 14. [Online] available from: http://www.culturemachine.net/index.php/cm/article/view/504/519 [Accessed 10/8/13.]

Hansen, F. A. Kortbek, K. J. and Grønbæk, K.

(2012) 'Mobile Urban Drama: Interactive Storytelling in Real World Environments'. New Review of Hypermedia and Multimedia. 18(1-2): 63-89.

Hardt, M. and A. Negri (2009) Commonwealth. Cambridge, Mass. and London: Harvard University Press.

Hardt, M. and A. Negri (2005) Multitude. St Ives: Penguin.

Hardt, M. and A. Negri (2001) Empire. Cambridge, Mass. and London: Harvard University Press.

Jacobs, M. (2012) 'Click, click, click, click. Zynga and the Gamification of Clicking’. Game Journal. [Online] available from: http://www.gamejournal.it/click-click-click-clickzynga-and-the-gamification-of-clicking/\#.U1_T7fldV54 [Accessed 29/4/14]

Jenkins, H. (2006) Fans, Bloggers and Gamers. New York: NYU Press.

Jenkins, H. and N. Carpentier (2013) 'Theorizing Participatory Intensities: A conversation about participation and politics'. Convergence. 19(3): 265-286.

Juris, J. (2012) 'Reflections on \#Occupy Everywhere: social Media, public space and emerging logics of aggregation’. American Ethnologist. 39(2): 259-279.

Kavada, A. (2013) 'Internet Cultures and Protest Movements'. B. Cammaerts, A. Mattoni and P. McCurdy (eds) Mediation and Protest Movements. Bristol and Chicago: Intellect. 75-94.

Lander, R. (2013) The Memory Dealer. Bristol, Watershed: U-Soap Media Productions. Performance: Pervasive Drama.

Latour, B., 1993. We Have Never Been Modern. Cambridge, Massachusetts: Harvard University Press.

Lim, M. (2012) 'Clicks, Cabs and Coffee Houses: Social Media and Oppositional Movements in Egypt 2004-2011'. Journal of Communication. 62. 231-248.

Lovink, G. (2011). Networks without a cause. Amsterdam: Institute of Network Cultures.

Madianou, M. and D. Miller (2013) Polymedia: Towards a New Theory of Digital Media in Interpersonal Communication . International Journal of Cultural Studies. 16(2): 169187.

Macho, T. (2013) 'Second-Order Animals: Cultural Techniques of Identity and Identification'. Theory, Culture \& Society. 30(6): 30-47. 
Madianou, M. (2014) Smartphones as polymedia. Journal of Computer-Mediated Communication. 19(3): 667-680.

Manzerolle, V. (2010) 'Mobilizing the Audience Commodity: Digital Labour in a Wireless World'. Ephemera. 10(3-4): 455-469.

Meikle, G. (2008) 'Whacking Bush: Tactical Media as Play', in Boler, M. (ed.), Digital Media and Democracy: Tactics in Hard Times. London: MIT Press. 367-382.

Merrifield, A. (1993) 'Place and Space: A Lefebvrian reconciliation'. Transactions of the Institute of British Geographers. 18(4): 516-531.

Morgan, D. (1996) 'Focus Groups'. Annual Review of Sociology. 22(1). 129-152.

Mol, A. 2002. The Body Multiple. Durham and London: Duke University Press.

Morozov, E. (2009a) 'Iran: Downside to the "Twitter Revolution”'. Dissent 56: 10-14.

Morozov, E. (2009b) ‘Moldova’s Twitter Revolution’. Foreign Policy. [Online] available from:

http://www.cc.gatech.edu/ beki/cs4001/Morozov.pdf

[Accessed 23/4/14]

Morozov, E. (2011) The Net Delusion. St Ives: Penguin.

Morozov, E. (2013) To Save Everything, Click Here. London: Penguin.

Moving Experience (2010) 'Moving Experience'. [Online] available from: http://www.nottingham.ac.uk/moss/research/moving-experience.aspx [Accessed 27/2/15]

Nack, F. and A. Waern (2012) 'Mobile Digital Interactive Storytelling: A Winding Path'. New Review of Hypermedia and Multimedia. 18(1-2): 3-9.

Parikka, J. (2014) ‘Cultural Techniques of Cognitive Capitalism’. Cultural Studies Review. 20(1): 30-52.

Passavant, P. A. \& J. Dean (eds) (2004) Empire's New Clothes: Reading Hardt and Negri. London: Routledge.

Pickerill, J. (2003) Cyberprotest: Environmental Activism On-line. Manchester: Manchester University Press.

Prasad, A. (2005) 'Making Images/Making Bodies'. Science, Technology \& Human Values. 30(2): 291-316.

Puig de la Bellacasa, M. (2009) 'Touching Technologies, Touching Visions. The Reclaiming of Sensorial Experience and the Politics of Speculative Thinking'. Subjectivity. 28: 297315.

Puig de la Bellacasa, M. (2011) 'Matters of Care in Technoscience: Assembling Neglected Things'. Social Studies of Science. 41(1): 85-106.

Rheingold, H. (2002) Smartmobs: the next social revolution? Cambridge, MA: Basic Books.

Schraube, E. and Sørensen, E. (2013) 'Exploring sociomaterial mediations of human subjectivity'. Subjectivity. 6: 1-11.

Star, S. L., 1991. 'Power, Technology and the Phenomenology of Conventions: On Being Allergic to Onions'. In J. Law ed. A Sociology of Monsters: Essays on Power, Technology and Domination. Routledge: London and New York. 26-56.

Terranova, T. (2012) ‘Attention, Economy and the Brain’. Culture Machine, 13. [Online] available from: http://www.culturemachine.net/index.php/cm/article/view/465/484 [Accessed 15/10/12]

Turkle, S. (1995) Life on the Screen. New York: Touchstone.

Turkle, S. (2011) Alone Together. New York: Basic Books.

Tuters, M. (2012) 'From Mannerist Situationism to Situated Media'. Convergence. 18(3): 267-282.

Uzelman, S. (2011) 'Media Commons and the Sad Decline of Indymedia'. The 
Communication Review. 14(4): 279-299.

Winthrop-Young, G. (2013) 'Cultural Techniques: Preliminary Remarks’. Theory, Culture \& Society. 30(6): 3-19.

Wittel, A. (2001) Toward a network sociality. Theory, Culture \& Society. 18(6): 51-76. 